\section{SciVerse ScienceDirect}

Procedia Technology 5 (2012) $491-499$
Procedia

Technology

CENTERIS 2012 - Conference on ENTERprise Information Systems / HCIST 2012 - International Conference on Health and Social Care Information Systems and Technologies

\title{
Cloud Computing Implementation Level in Portuguese Companies
}

\author{
Osvaldo Ferreira $^{\mathrm{a}}$, Fernando Moreira ${ }^{\mathrm{a} *}$ \\ ${ }^{a}$ Universidade Portucalense, DICT, Porto, Portugal \\ osvaldoferreir@gmail.com,fmoreira@upt.pt
}

\begin{abstract}
The Information Technology (IT) has suffered many advances in recent years due to the development of new hardware and software solutions. These major changes have been noted in recent times in how we interact with applications and services in IT. Cloud Computing provides services and applications over the Internet with the promise of infinite capacity and service models of "pay-as-you-go". This paper describes the main characteristics of Cloud Computing, future expectations and analyzes the state of knowledge and implementation in Portuguese companies.
\end{abstract}

(C) 2012 Published by Elsevier Ltd. Selection and/or peer review under responsibility of CENTERIS/SCIKA -

Association for Promotion and Dissemination of Scientific Knowledge Open access under CC BY-NC-ND license.

Keywords: cloud computing; virtualization; portugal; information technology

\section{Introduction}

In the society of the twenty-first century, technology is constantly evolving, with a production and sharing information as never seen before. With a view to preserving and sharing such information, companies turn to

\footnotetext{
* Corresponding author.

E-mail address: fmoreira@uportu.pt.
} 
technology as support equipment, because never like today was the processing power of computers so great and telecommunications links were so cheap and reliable, never like today was possible to store so much information in so little space.

The IT sector is one that undergoes more changes and evolves more rapidly in a short period of time. The requirements that are beginning to emerge are increasingly diverse and technologies have covered more areas. When the business needs begin to emerge in greater quantity, companies have to keep pace with the evolution and are thus more competitive.

This is a relatively new technology, and there is still some confusion with other currently available technologies such as Grid Computing and Virtualization. Initially, this confusion is acceptable, since the cloud computing takes advantage of the specific features of those two technologies, but it goes further.

Currently there is no consensus on the definition of cloud computing, however it is commonly agreed that the definition made by the National Institute of Standards and Technology is the closest and the more accurate. NIST defines cloud computing as "a model for enabling convenient, on-demand network access to a shared pool of configurable computing resources (e.g., networks, servers, storage, applications, and services) that can be rapidly provisioned and released with minimal management effort or service provider interaction. For Gartner (the world's leading research and advice on Information Technology): "Cloud Computing is a style of computing in which scalable and elastic IT-enabled capabilities are delivered as a service to external customers using Internet technologies." [1].

In a more detailed description, Cloud Computing refers to the access of computing resources that are generally owned and operated by an external supplier with a well-established infrastructure in multiple data centers. These vendors have a set of resources that can be used on the form of pay-as-you-go, leading to a minimum initial investment and can go up and down according to the needs of the organization. All services are delivered over the Internet and users don't have to know how it works or how they are deployed, they only need to know how to use it and how much it costs.

This paper aims at an introduction to Cloud Computing, talking about the technologies that preceded it, its main characteristics and conducts an assessment to the level of implementation in the Portuguese companies.

\section{Overview}

Until the emergence of cloud computing, other technologies, each with its own specificities, were already used separately or together so that organizations were able to optimize their IT resources.

Cloud Computing appears as a combination of all of these technologies, gathering from them some major capabilities in order to give users a better experience. And to accomplish that, Cloud Computing is composed by five essential characteristics, three models of service and five deployment models.

\subsection{Major technologies}

The evolution of computing has suffered some changes trough out the years. At some point of this evolution some other technologies were born and used. To help understand the importance of our current transition into a computing world dominated by cloud computing, it was important to mention them.

Virtualization is one of those technologies, consisting of the technique used to hide the physical characteristics of computing resources so that other systems, applications or end users can interact with these features. It was implemented by IBM in 1972 with the system 370. This was the first commercial computer entirely designed for virtualization, with the operating system CP / CMS, allowing running multiple instances simultaneously. [2] 
Despite the huge initial success, it was soon set aside. With the relative low price of the hardware, companies have chosen to place servers dedicated to each service, but today was prominent being the first choice of companies to consolidate servers, reduce energy and space in the datacenter.

The Grid Computing can be defined as a system supporting the execution of parallel applications containing heterogeneous distributed resources, providing a consistent and inexpensive access to resources, regardless of user location. Grid computing technology enables aggregate dispersed computing resources into a single "virtual supercomputer" by accelerating the implementation of several parallel applications, often using the processing power unused. Networks (grids) became possible in recent years due to the large performance improvement and cost reduction, both in computer networks as in the microprocessors. [3]

Utility Computing involves the rental of computing resources such as hardware, software and network services (bandwidth), according to the needs of customers and almost automatically. In other words, what was previously considered a product is now treated as a service. A service of "utility" in the image of electricity or phone. This idea was introduced by John McCarthy at MIT (Massachusetts Institute of Technology) in 1961 when he said: "If computers of the kind I have advocated become the computers of the future, then computing may someday be organized as a public utility just as the telephone system is a public utility... The computer utility could become the basis of a new and important industry." [4].

\subsection{Cloud Computing, essential characteristics}

Both in theory and in practice cloud computing has become relatively consistent in a remarkably brief period of time. The following five essential characteristics added to that.

On-demand self-service - A consumer may request new or increasing computing capabilities. This increase is done automatically without any human interaction on the part of the service provider.

Broad network access - Broad access to the network means that cloud services are accessible from any platform. They are used in standard mechanisms that promote the use of heterogeneous platforms. The client can access services of various types of platforms such as mobile phone or personal computer, among others.

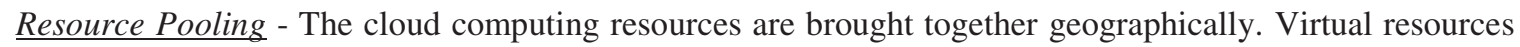
are dynamically allocated or reallocated by the customer as needed. The client does not control the actual location of the resources that you are using, and has only access to information like the country or the datacenter. The types of resources used are: storage, processing, memory, bandwidth, and virtual machines.

Rapid Elasticity - Elasticity is defined as the ability to allocate resources more or less at the time they are needed, with speed and agility. In the consumer's perspective, the cloud seems to be endless, with unlimited resources; it can acquire more or less computing power as needed for your applications. This is one of the main features that make Cloud Computing a very attractive service.

Measured Service - All services are controlled and monitored automatically in the cloud, so the consumer can optimize their consumption and optimize their use of the cloud. On the other hand, allows the supplier to have a true reading of the service offered and its respective charge.

\subsection{Cloud Computing, Service models}

Understanding of the key aspects of cloud computing and its core architectures is vital to pursuing the right cloud computing solution. Each company chooses a cloud service and a deployment model based on their specific business, operational, and technical requirements. Here we will in short introduce the three cloud 
service models (IaaS, PaaS, SaaS) which can serve as a foundation for further developing your understanding of cloud computing and its capabilities.

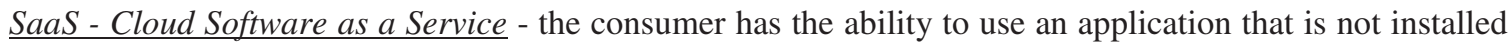
in his personal computer, it is in the cloud and is accessed through the Internet.

PaaS - Cloud Platform as a Service - it's the capacity that the customer has to move to the cloud applications designed and developed by him using certain programming language and tools provided by the Cloud supplier.

IaaS - Cloud Infrastructure as a Service - is the availability of virtual machines to the customer, with processing facilities, data storage, servers and network components. With this type of service, the provider "rents" the machines to the customer, and this pays for usage or usage time. The computing environment is provided as requested by the client, and he does not need to worry about the costs of maintaining or upgrading the used hardware.

\subsection{Cloud Computing, Deployment models}

Deploying cloud computing can differ depending on requirements, and the following five deployment models have been identified, each with specific characteristics that support the needs of the services and users of the clouds in particular ways.

Private Cloud -The Private Cloud model predicts that the infrastructure supporting the Cloud is used by only one organization. This may be responsible for managing or being managed by an external company and may or may not be within the premises of the organization. [5]

Community Cloud -This model predicts that the Cloud Infrastructure support is shared by several organizations, which form a specific community with common interests. Its operation can be made by all organizations or by an external company and can be inside or outside the premises of these organizations. [5]

Public Cloud - The Public Cloud model predicts that the infrastructure is available to the general public or a large number of organizations and is managed and controlled at all levels, by a company that provides services in the Cloud. [5]

Hybrid Cloud - The Hybrid Cloud model predicts that the infrastructure is a combination of two types cloud, such as private and public. [5]

Partner Cloud - The Cloud Partner model predicts that the infrastructure is in a trusted cloud service supplier and is managed in partnership with the same supplier. The organization can use its resources in the cloud and/or provides them to other organizations.

\section{Methodology}

The purpose of this section is to describe in detail the procedure performed to collect research data, in order to justify how this study was prepared.

The main feature of scientific method is the organized research, rigorous control of use of observations and theoretical knowledge. The current study was based on quantitative research methodology.

The data collection for quantitative research using questionnaires requires special care, not enough to collect responses on issues of interest, but how to analyze them statistically for proper validation of results.

Aspects such as sample size, what kind of elaborate questionnaire, wording of questions, the forms of data analysis, margin of error, the process of selection of individuals who should compose the sample, among others, are some important points that should be observed carefully for any research. 
For the selected study it was used a quantitative research, since it is more appropriate to determine opinions and attitudes of respondents based on structured questionnaires. In quantitative research, data are collected through a structured questionnaire clear and objective to ensure uniformity in the understanding of respondents and consequent standardization of results.

The questionnaire method is recommended, according to Raymond and Luc Van Quivy Campenhoudt [6], when you want to know a population (lifestyles, customs, behaviors, values and opinions), to analyze a social phenomenon and in all cases where it is necessary to question a large number of people on a given issue. The aim of this study was to obtain answers that will measure the level of implementation of Cloud Computing in Portuguese companies and for the collection of data was used a questionnaire survey.

In relation to companies surveyed, they were distributed throughout the country most notably the two largest cities, Lisbon and Porto. In the sector of activity, information technology and education were the two areas with more companies involved.

\section{The level of implementation of Cloud Computing in Portuguese Companies}

At a time when the world is increasingly dependent on IT, new techniques and processes appear in order to make us get to information faster. Internet has revolutionized society, the way people communicate socially, how organizations work, how regardless of our geographical location we have access to information, how to share information and knowledge.

Over the past 10 years, Portugal has doubled the number of Internet access [7]. With this phenomenon came another, much more recent, but equally important, the Cloud Computing. This new technology will allow the possibility of sharing computing resources via the Internet as a service, making it even easier to access information and further revolutionize the way we interact with others and the direction / strategy of companies whether small, medium or large multinationals.

Therefore it became pertinent to conduct a survey to Portuguese companies in order to ascertain the level of implementation of Cloud Computing. For this it was made a quantitative study based on an online questionnaire which could contain between 11 and 19 questions based in the previous responses. One hundred and sixty were considered valid responses to the questionnaire put online for 83 days.

\subsection{Survey Results}

After processing and analysis of data derived from the valid questionnaires, it appears that after sending the report to companies from all sectors, the Information Technology sector was one that stood out with nearly $30 \%$ of responses. $44 \%$ of enterprises are micro or small enterprises and have no IT department. For the geographical distribution of firms surveyed, Oporto and Lisbon, stood out, and $70 \%$ of businesses is located in these two parts of the country.

\subsubsection{Cloud Computing Level of Knowledge}

Regarding the level of knowledge of cloud computing, it is noted that in Portugal there is already a widespread interest about this new technology, only $26 \%$ of respondents does not know what cloud computing is, in contrast to the $45 \%$ who already have the minimum knowledge on this technology and $19 \%$ that already have a consolidated knowledge. This information can be seen in figure 1 . 


\section{Level of knowledge of Cloud Com}

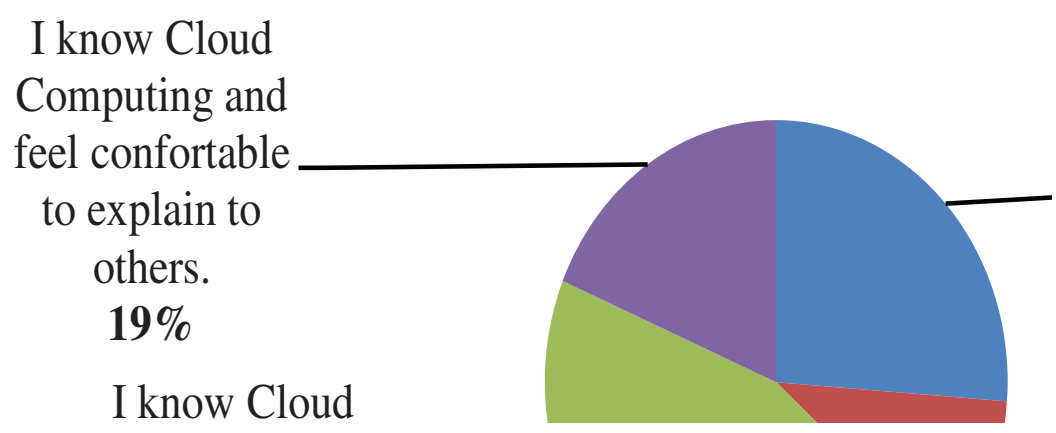

Fig. 1 - Level of Knowledge of Cloud Computing

This knowledge and curiosity about Cloud Computing is real implemented, as $51 \%$ of respondents already use services available in the Cloud. This value may be higher, because some services such as backup or email, which qualify as cloud services, are not yet seen as cloud services for many companies.

\subsection{Main reasons for adopting Cloud Computing}

Despite the many advantages that cloud computing brings to the companies, when questioned, the main reason is related to economics, including spending on hardware, software and IT support. Immediately afterwards is also highlighted the increase in computing power that Cloud Computing can provide, which reveals that the companies surveyed are well aware not only how they can save costs but also optimize the resources available in order to improve business processes. Such information can be seen in figure 2 .

Moreover, unlike some Cloud service providers advertise, creating platforms for Business Continuity and Disaster Business, not yet called to the attention of the companies surveyed. This is due to concerns that Portuguese companies have with the privacy of information and with the loss of control of that information. In the following figure there are all the main reasons for the adoption of Cloud Computing services. 


\section{Main reasons to use the services of Cloud Com}

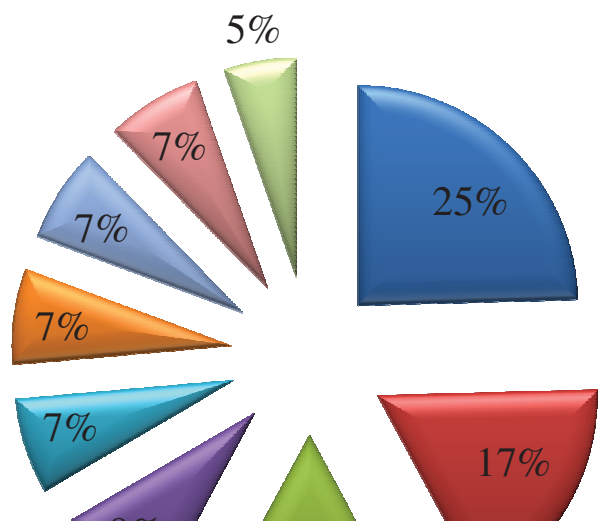

$\square$ Avoid unnecessar software and IT si

๑ Increased comput

$\square$ Scalability and fle

$\square$ Diversification of

$\square$ Increase the redur

$\square$ Removal of econc

1rmantndm in ...n

Fig. 2 - Main reasons to use the services of Cloud Computing

\subsection{Type of Cloud and services adopted}

Regarding the type of cloud and following figure 3, most companies use the services provided by Public Cloud and SaaS is the services layer most widely used, especially the e-mail services like Gmail, Hotmail, and Storage services like DropBox or Google Docs. On the other hand about 25\% of companies have implemented in their companies a Private Cloud, which already shows an advanced knowledge of this technology.

\section{Type of Cloud used by the companie:}

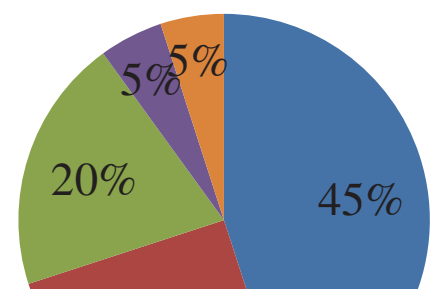

Fig. 3 - Type of Cloud used by companies surveyed

For companies that are still in the planning phase of the study and the adoption of some type of service provided by Cloud, Public Cloud is also the top choice and SaaS services like email and storage are also plans for Portuguese companies in near future, this seems to be the starting point in the adoption of Cloud Computing. 


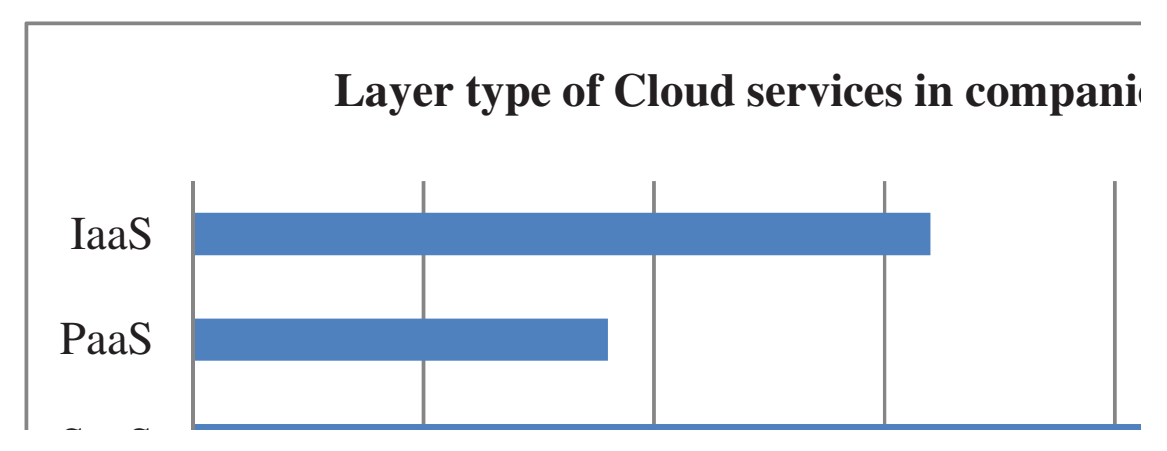

Fig. 4 - Layer type of Cloud services in companies surveyed

Although the information on Cloud Computing is already available in various formats, Portuguese companies show strong curiosity about the subject, and about $74 \%$ of respondents want to receive more information.

As in other European countries, Portugal, gives the first steps into the adoption of Cloud Computing. Although the level of implementation is still small, companies are aware of all the new technologies that arise and how they may use them for their own benefit. The economic benefits are the major concern for Portuguese companies and calmly using the services provided by Public Cloud they are gaining knowledge and begin looking for other services and other types of Cloud.

\section{Conclusion}

In the global market we live in nowadays, companies must innovate and try to get the most success with the resources they have available. This requires that employees, partners and suppliers use more tools to work promoting collaborative innovation

Cloud Computing despite presenting itself as a new technology, it seems that was always present, given the notoriety and the way the available services are used by companies. But there are still barriers that may not condition the average user, who fully trust their mail to Google or Hotmail, but that condition companies that are planning gains and improvements in large scale.

The low confidence in information security, both in their migration, enterprise to Cloud as their management and maintenance out of doors by others, is undoubtedly the greatest obstacle to the growth of this technology. It contributed greatly to the fact that there is still no strict standardization of processes over which, providers should base their offerings and consumers to assess their needs. Without this standardization becomes virtually impossible in the first analysis to verify who provides the best service, which is the most advantageous, which has the highest quality.

Each cloud service provider bases its offer on his best skills and introduces himself as the best choice. In the European market, where Portugal fits there are still some delays when compared with other countries in North America and in particular the United States. This delay is due not only to the fact that European legislation is very restrictive for the data transfer processes within the EU and outside it, but also because IT managers do not feel safe, when companies information is out of the theirs datacenters. Nevertheless, and as the economic benefits speak louder, many of them are already beginning to take its first steps, building Private Clouds, gaining know-how and thus preparing for the future to embrace other Cloud.

Cloud Computing has evolved continuously, but these developments have emerged obstacles and problems that need to be solved. Despite the rapid growth at business level, there are still many open questions, which make it appropriate for further analysis at the level of maturity of Cloud Computing in Portuguese Companies. 


\section{References}

[1] Gartner, Inc. (03 de 07 de 2011). Gartner Newsroom. Obtido de Gartner Highlights Five Attributes of Cloud Computing: http://www.gartner.com/it/page.jsp?id=1035013

[2] IBM. (2010). IBM Archives. Obtido em 2011, de History of IBM 1960: http://www03.ibm.com/ibm/history/history/decade_1960.html

[3] Strickland, J. (2010). How Stuff Works. Obtido em 2011, de How Grid Computing Works: http://computer.howstuffworks.com/gridcomputing5.htm

[4] Biswas, S. (2011). A History of Cloud Computing. Obtido em 2011, de CloudTweaks: http://www.cloudtweaks.com/2011/02/ahistory-of-cloud-computing/

[5] Mell, P. (2009). Effectively and Securely Using the Cloud Computing Paradigm. NIST.

[7] Stats, I. W. (2012). Obtido em 2011, de Internet World Stats - Usage and Population Statistics: http://www.internetworldstats.com/stats4.htm

[8] The National Institute of Standards and Technology (NIST). (2010). Information Technology Laboratory. Obtido em 06 de 06 de 2011, de NIST Cloud Computing Program: http://www.nist.gov/itl/cloud/index.cfm

[9] UN Documents. (1987). Obtido em 2011, de Report of the World Commission on Environment and Development: Our Common Future : http://www.un-documents.net/wced-ocf.htm

[10] Petri, G. (3 de Março de 2011). Vivek Kundra's Decision Framework for Cloud Computing Migration . Cloud Computing Jornal.

[11]GTSI. (2011). Cloud Computing - Building a Framework for Successful Transition. http://www.gtsi.com/cms/documents/WhitePapers/Cloud-Computing.pdf: GTSI. 